\title{
A SIMPLIFIED TWO-NODE COARSE-MESH FINITE DIFFERENCE METHOD FOR PIN-WISE CALCULATION WITH SP3
}

\author{
Wenbo Zhao ${ }^{1}$, Yingrui Yu ${ }^{1}$, Xiaoming Chai ${ }^{1}$, Zhonghao Ning ${ }^{1}$, Bin Zhang ${ }^{1}$, Yun Cai ${ }^{1}$, Kun \\ Liu $^{1}$, Xingjie Peng ${ }^{1}$, and Junchong Y $\mathbf{u}^{1}$ \\ ${ }^{1}$ Science and Technology on Reactor System Design Technology Laboratory, Nuclear Power \\ Institute of China \\ Chengdu, 610041, China
}

zhaowenbo.npic@gmail.com, yuyr78@163.com,chaixm@163.com,958968105@qq.com, jsszwtzb@163.com, caiy08@163.com,seraph.kliu@foxmail.com, pengxingjiets@126.com,

Npicyjc@163.com

\begin{abstract}
For accurate and efficient pin-by-pin core calculation of SP3 equations, a simplified twonode Coarse Mesh Finite Difference (CMFD) method with the nonlinear iterative strategy is proposed. In this study, the two-node method is only used for discretization of Laplace operator of the 0th moment in the first equation, while the fine mesh finite difference (FMFD) is used for the 2nd moment flux and the second equation. In the two-node problem, transverse flux is expanded to second-order Legendre polynomials. In addition, the associated transverse leakage is approximated with flat distribution. Then the current coupling coefficients are updated in nonlinear iterations. The generalized eigenvalue problem from CMFD is solved using Jacobi-Davidson method. A protype code CORCA-PIN is developed. FMFD scheme is implemented in CORCA-PIN as well. The 2D KAIST 3A benchmark problem and extended 3D problem, which are cell homogenized problems with strong absorber, are tested. Numerical results show that the solution of the simplified twonode method with $1 \times 1$ mesh per cell has comparable accuracy of FMFD with $4 \times 4$ meshes per cell, but cost less time. The method is suitable for whole core pin-wise calculation.
\end{abstract}

KEYWORDS: SP3, two-node, pin-wise

\section{INTRODUCTION}

With the design and calculation requirements of new and complex reactor types, such as MOX fuel, BWR, SCWR, and so on, traditional two-step framework based on single assembly homogenization is not accurate to capture the rapid changes in space and energy spectrum between adjacent assemblies and inner assembly. Compared to assembly homogenization, cell homogenization is expected to capture these rapid variations of flux. With the development of computer capabilities, pin-by-pin calculation has gained more research attention.

For a typical pressurized water reactor, the number of unknowns is more than 10 million, which is increased by three orders of magnitude compared to the traditional two-step method. Therefore, the efficiency of solving pin-by-pin problem is the key to the practical application. Several methods[1-6], 
such as the response matrix method, finite element method, global/local methods, and so on, have been proposed to improve high efficiency.

In this paper, a simplified two-node method based on nonlinear iterative strategy is used to solve the SP3 transport equation. The method is described in section 2 . The numerical results are shown in section 3 . In section 4 , we will give the conclusions.

\section{METHOD}

\subsection{SP3 Equations}

The SP3 equations used in this paper is shown as follows,

$$
\begin{gathered}
\left(-D_{g}^{0} \nabla^{2}+\Sigma_{r, g}\right) \varphi_{g}^{0}-2 D_{g}^{0} \nabla^{2} \varphi_{g}^{2}-\sum_{g^{\prime} \neq g} \Sigma_{s 0, g^{\prime} \rightarrow g} \varphi_{g^{\prime}}^{0}=\frac{1}{k_{e f f}} \chi_{g} \sum_{g^{\prime} \neq g} v \Sigma_{f, g^{\prime}} \varphi_{g^{\prime}}^{0} \\
-\frac{2}{5} D_{g}^{0} \nabla^{2} \varphi_{g}^{0}+\left(-\frac{4}{5} D_{g}^{0} \nabla^{2}-\frac{3}{5} D_{g}^{2} \nabla^{2}+\Sigma_{t r, g}\right) \varphi_{g}^{2}=0
\end{gathered}
$$

where $D_{g}^{0}=\frac{1}{3 \Sigma_{t r, g}}, D_{g}^{2}=\frac{3}{7 \Sigma_{t r, g}}, \varphi_{g}^{0}$ is $0^{\text {th }}$ moment of angular flux, $\varphi_{g}^{2}$ is $2^{\text {nd }}$ moment, the subscript $\mathrm{g}$ means energy group, the rest are customary symbols.

The old form of SP3 equations is used in this paper, in which $\varphi_{g}^{0}$ and $\varphi_{g}^{2}$ considering associated discontinuity factors are continuous at the interface between adjacent meshes and $-D_{g}^{0} \nabla \varphi_{g}^{0}$ and $-D_{g}^{2} \nabla \varphi_{g}^{2}$ are continuous as well. The rigorous form of SP3 equations [7] with correct interface continuity conditions will be considered in future.

\subsection{Two-node Method}

In two-node method, the current at the interface in two-node method is written as follows,

$$
J_{i}^{+}\left(h_{i} / 2\right)=\frac{2 D_{i} D_{i+1}}{f_{i+1}^{-} h_{i+1} D_{i}+f_{i}^{+} h_{i} D_{i+1}} \times\left(f_{i}^{+} \varphi_{i}-f_{i+1}^{-} \varphi_{i+1}\right)-\widehat{D}_{i}^{+} \times\left(f_{i}^{+} \varphi_{i}+f_{i+1}^{-} \varphi_{i+1}\right)
$$

where $\mathrm{h}$ is mesh size, $\mathrm{f}$ is discontinuity factor, $\widehat{D}_{i}^{+}$is current coupling coefficient which is updated in nonlinear iteration. If current coupling coefficient are equal to zero, the method degraded into fine mesh finite difference method (FMFD).

Then the coarse mesh finite difference (CMFD) discretization systems are established by substituting Eq. (3) into Eq. (1) and Eq. (2), which is written as follows,

$$
A x=k_{e f f} B x
$$

The structures of matrixes A and B are the same as ones of FMFD.

Since the $2^{\text {nd }}$ moment flux is one order of magnitude less than $0^{\text {th }}$ moment flux, only the $1^{\text {st }}$ moment currents at interface in Eq. (1) are treated with nonzero current coupling coefficients. The rest of currents in Eq. (1) and Eq. (2) are treated by FMFD. On the other hand, more strictly criterion on flux convergence would be required to ensure the convergence of $3^{\text {rd }}$ moment currents coupling coefficients. Therefore a simplified two-node method is used in this paper. 
To update the current coupling coefficients, the transverse integration is employed to Eq. (1), and the transverse flux along $\mathrm{x}$-direction satisfies

$$
-D_{g}^{0} \frac{d^{2}}{d x^{2}} \varphi_{g}^{0}(x)+\Sigma_{r, g} \varphi_{g}^{0}(x)-2 D_{g}^{0} \frac{d^{2}}{d x^{2}} \varphi_{g}^{2}-\sum_{g^{\prime} \neq g} \Sigma_{s 0, g^{\prime} \rightarrow g} \varphi_{g^{\prime}}^{0}(x)=\frac{1}{k_{e f f}} \chi_{g} \sum_{g^{\prime}=1}^{G} v \Sigma_{f, g^{\prime}} \varphi_{g^{\prime}}^{0}(x)-L_{g}(
$$

where $\mathrm{L}$ is transverse leakage term.

The transverse leakage term $\mathrm{L}$ is approximated using flat distribution as follows

$$
\bar{L}_{x, g}=\frac{J^{0}\left(h_{y} / 2\right)-J^{0}\left(-h_{y} / 2\right)}{h_{y}}+\frac{J^{0}\left(h_{z} / 2\right)-J^{0}\left(-h_{z} / 2\right)}{h_{z}}+\frac{J^{2}\left(h_{y} / 2\right)-J^{2}\left(h_{y} / 2\right)}{h_{y}}+\frac{J^{2}\left(h_{z} / 2\right)-J^{2}\left(-h_{z} / 2\right)}{h_{z}}
$$

The transverse $0^{\text {th }}$ moment is expanded to second-order Legendre polynomials satisfying

$$
\varphi(x)=b_{0}+b_{1} P_{1}\left(\frac{2 x}{h_{x}}\right)+b_{2} P_{2}\left(\frac{2 x}{h_{x}}\right), x \in\left[-h_{x} / 2, h_{x} / 2\right]
$$

where $P_{i}$ is the $i^{\text {th }}$ Legendre polynomials.

According to orthogonal properties of Legendre polynomials, $b_{0}$ equals to mesh average flux which is solved from Eq. (4) in the previous non-linear iteration. Therefore, there are four unknows, $b_{1}$ and $b_{2}$ of adjacent meshes, $i$ and $i+1$, for each group. Multiplying the two sides of Eq. (5) by $\mathrm{P}_{0}$ and then integrating it over each mesh, we obtain two equations for each group. The continuity conditions of flux and current are used to get the rest two equations. Then four unknows are determined by these equations. Then currents $J_{i}^{+}\left(\frac{h_{i}}{2}\right)$ at the interface are calculated using Eq. (7). Finally, the coupling coefficients are updated as follows,

$$
\widehat{D}_{i}^{+}=\frac{1}{\left(f_{i}^{+} \varphi_{i}+f_{i+1}^{-} \varphi_{i+1}\right)} \times\left(\frac{2 D_{i} D_{i+1}}{f_{i+1}^{-} h_{i+1} D_{i}+f_{i}^{+} h_{i} D_{i+1}} \times\left(f_{i}^{+} \varphi_{i}-f_{i+1}^{-} \varphi_{i+1}\right)-J_{i}^{+}\left(\frac{h_{i}}{2}\right)\right)
$$

The iteration strategy of the coupling coefficients is the standard non-linear iteration strategy shown below,

$0 \quad$ Initialize coupling coefficients

1 Solve Eq. (4) using methods introduced in Sec. 2.3

2 Update coupling coefficients using Eq. (8)

3 Check convergence of coupling coefficients. If convergence, finished. Otherwise, jump to 1

And we set the convergence criterion is equal to 0.001 in this paper.

\subsection{Iteration Method of CMFD}

The mainly computing burden is to solve Eq. (4). As well known, this k-eigenvalue problem is a generalized non-Hermitian eigenvalue problem in which the largest eigenvalue in real need to be solved. Jacobi-Davidson method, which a kind of subspace method, is used to solve this eigenvalue problem. The subspace is expanded by the approximate solution of the Jacobi orthogonal correction equation as follows, 


$$
\left(I-\frac{K^{-1} u u^{T}}{u^{T} K^{-1} u}\right) K^{-1}(A-\theta B)\left(I-\frac{K^{-1} u u^{T}}{u^{T} K^{-1} u}\right) t=-\left(I-\frac{K^{-1} u u^{T}}{u^{T} K^{-1} u}\right) K^{-1} r
$$

where $r=A u-\theta B u$ is residual, $\mathrm{t}$ is correction, $\mathrm{K}$ is preconditioner of $A-\theta B, \mathrm{u}$ is approximation eigenvector and $\theta$ is associated approximation eigenvalue. Since Eq. (9) is required to be solved approximately, Jacobi-Davidson method is more efficient than the Arnoldi method to solve generalized eigenvalue problem. In this paper, GMRES iterative solver with Jacobi preconditioner is used and the relative tolerance is set to $1 \mathrm{E}-3$.

The iterative methods are implemented based on SLEPc v3.9[8] and PETSc v3.9[9] which are famous open source libraries providing a large suite of parallel eigenvalue and linear system solvers. Then CORCA-PIN code is developed.

\section{CALCULATIONS}

\subsection{D 4 Groups ARI Benchmark problem}

The original problem [10] is a three-dimensional 1/4 symmetry ARI core loaded with 157 assemblies with 4 groups cell homogenized cross sections. In order to obtain the mesh-independent solution with less calculation, we use two-dimensional geometry, and the reflective boundary conditions are used in the axial directions. The homogenized cells are divided into $1 \times 1,2 \times 2,4 \times 4$ meshes respectively. The reference solution is calculated by FMFD using $32 \times 32$ meshes per cell, and the mesh size is about 0.04 $\mathrm{cm}$, which ensures that the mesh discretization error of the reference solution is negligible.

The Keff and power distribution results are given in Table 1 and Fig. 1. The error of Keff by two-node method is less than $202 \mathrm{pcm}$. Keff calculated by two-node method using $1 \times 1$ mesh is accurate than that of FMFD using $4 \times 4$ meshes. The maximum relative error of the power distribution of two-node method using $1 \times 1$ mesh per cell is $3.3 \%, 2 \times 2$ is $2.1 \%$, and $4 \times 4$ is $0.6 \%$. The power errors calculated by two-node method using $2 \times 2$ meshes per cell are less than that of FMFD using $4 \times 4$ significantly. And the accuracy of two-node method using $1 \times 1$ mesh per cell is similar with that of FMFD using $4 \times 4$ except on a few cells.

FMFD is of first-order accuracy for nonuniform material case, which explains the performance on this problem. It occurred frequently that the reactivity errors of two-node method using $1 \times 1$ mesh per cell is less than ones using $2 \times 2$ mesh per cell. But calculation with $2 \times 2$ mesh per cell have higher accuracy on flux and power distribution than calulations with $1 \times 1$ mesh per cell.

Table I. Keff Comparison of 2D 4G Benchmark Problem

\begin{tabular}{|c|c|c|}
\hline Mesh & $\begin{array}{c}\text { Keff (Error of reactivity, } \\
\text { pcm) of two-node }\end{array}$ & $\begin{array}{c}\text { Keff (Error of reactivity, } \\
\text { pcm) of FMFD }\end{array}$ \\
\hline $1 \times 1$ & $0.93972(145)^{*}$ & $0.96798(3251)$ \\
\hline $2 \times 2$ & $0.94023(202)$ & $0.94940(1229)$ \\
\hline $4 \times 4$ & $0.93893(54)$ & $0.94178(377)$ \\
\hline $32 \times 32$ & - & $0.93845(-)$ \\
\hline
\end{tabular}

$*$ the errors of reactivity are listed in brackets. 


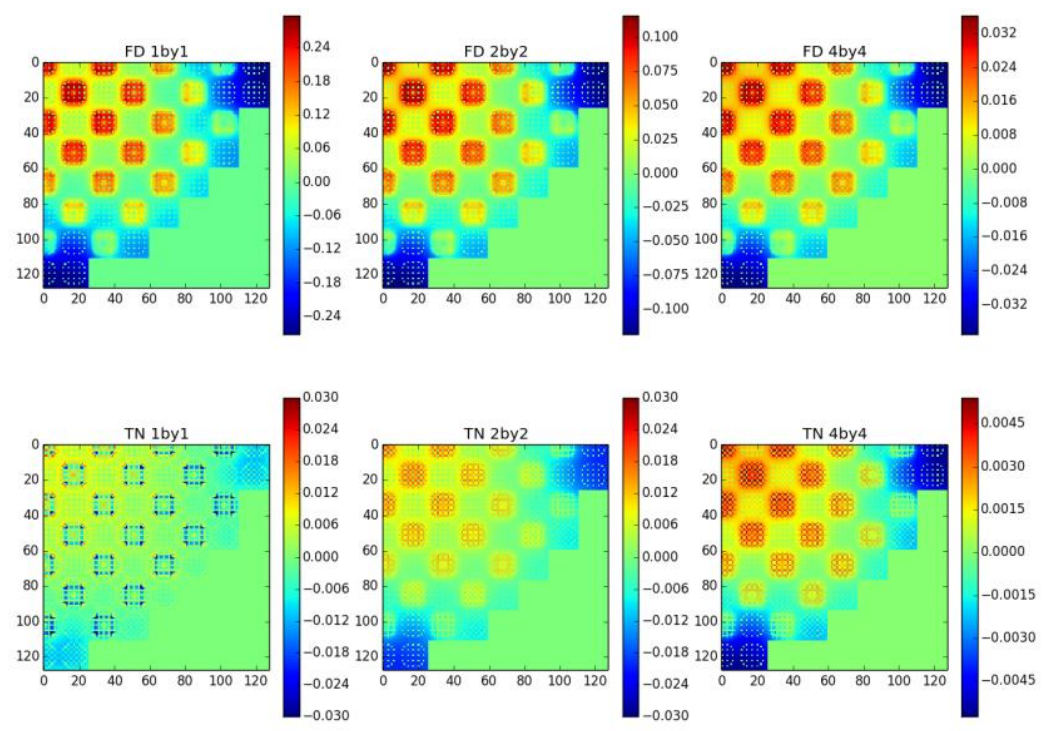

"FD" means finite difference, "TN" means two-node

" $\mathrm{n}$ by $\mathrm{n}$ " means mesh division of $\mathrm{n} \times \mathrm{n}$ meshes per pin is used

Figure 1. Relative Error of Power of 2D 4G Problem

\subsection{D KAIST 3A Benchmark problem}

The 2D KAIST 3A benchmark problem[11] provides 7-group cell homogenized cross section, including UOX fuel rods, MOX fuel rods, control rods, and poison rods. The core layout is shown in Fig. 2. The discretization errors of two-node method are validated using different meshes and compared with FMFD. The homogenized cells are divided into $1 \times 1,2 \times 2,4 \times 4$ meshes respectively. The reference solution is calculated by FMFD using $32 \times 32$ meshes per cell.

\begin{tabular}{|c|c|c|c|}
\hline $\begin{array}{l}\text { UOX-2 } \\
(\text { BA1C) }\end{array}$ & $\begin{array}{c}\text { UOX-2 } \\
\text { (CR) }\end{array}$ & MOX-1 & UOX -1 \\
\hline $\begin{array}{c}\text { UOX-2 } \\
\text { (CR) }\end{array}$ & $\begin{array}{c}\text { MOX-1 } \\
(\mathrm{BA} 8)\end{array}$ & $\begin{array}{c}\text { UOX-2 } \\
\text { (CR) }\end{array}$ & UOX-1 \\
\hline MOX-1 & $\begin{array}{c}\mathrm{UOX}-2 \\
\text { (CR) }\end{array}$ & UOX-1 & \\
\hline UOX-1 & UOX-1 & & \\
\hline
\end{tabular}

\section{Figure 2. Layout of KAIST 3A Benchmark Problem}

The Keff comparison is given in Table 2. The error of Keff by two-node method is less than $100 \mathrm{pcm}$. Keff calculated by two-node method using $1 \times 1$ mesh is more accurate than that of FMFD using $2 \times 2$ meshes, even $4 \times 4$ meshes. In addition, the maximum relative error of the power distribution of two-node method using $1 \times 1$ mesh per cell is $3.9 \%, 2 \times 2$ is $2.6 \%$, and $4 \times 4$ is $0.7 \%$. The relative error of pin-wise power distribution is shown in Fig. 3. The comparison results of relative errors are similar to the previous section. 
Table II. Keff Comparison of KAIST 3A Benchmark Problem

\begin{tabular}{|c|c|c|}
\hline Mesh & $\begin{array}{c}\text { Keff (Error of reactivity, } \\
\text { pcm) of two-node }\end{array}$ & $\begin{array}{c}\text { Keff (Error of reactivity, } \\
\text { pcm) of FMFD }\end{array}$ \\
\hline $1 \times 1$ & $0.97085(63)^{*}$ & $0.98769(1820)$ \\
\hline $2 \times 2$ & $0.97119(100)$ & $0.97639(648)$ \\
\hline $4 \times 4$ & $0.97050(27)$ & $0.97208(194)$ \\
\hline $32 \times 32$ & - & $0.97025(-)$ \\
\hline
\end{tabular}
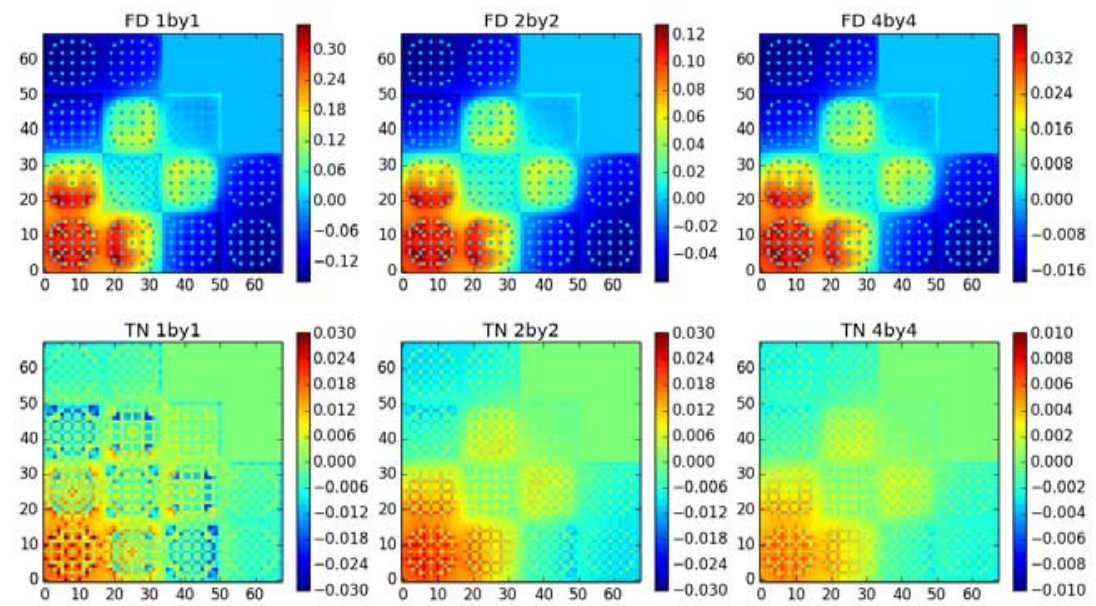

Figure 3. Relative Error of Power of KAIST 3A Benchmark Problem

\subsection{D Self-constructed Problem Using Assembly of KAIST 3A}

There are six types assembly in KAIST 3A benchmark problem. We use them to construct a threedimensional 1/4 reactor shown in Fig. 4. The active zone of the reactor is $365.76 \mathrm{~cm}$ high, and both the upper and lower reflection layers are $25.4 \mathrm{~cm}$ high. There are four kinds of grid, including $1.26 \mathrm{~cm} \times 1.26 \mathrm{~cm} \times 2.54 \mathrm{~cm}, \quad 0.63 \mathrm{~cm} \times 0.63 \mathrm{~cm} \times 2.54 \mathrm{~cm}, \quad 0.315 \mathrm{~cm} \times 0.315 \mathrm{~cm} \times 2.54 \quad \mathrm{~cm}, \quad$ and $0.315 \mathrm{~cm} \times 0.315 \mathrm{~cm} \times 1.27 \mathrm{~cm}$. The reference solution is calculated by two-node method using the finest grid. It is noted that the grid with $1.26 \mathrm{~cm} \times 1.26 \mathrm{~cm}$ mesh size is the same as the grid of $1 \times 1$ mesh per cell shown in section 3.1 . For the coarsest mesh of $1.26 \mathrm{~cm} \times 1.26 \mathrm{~cm} \times 2.54 \mathrm{~cm}$, the number of grids is about 3 million, and the number of unknows is about 42 million.

The Keff comparison is shown in Table 3. The errors of Keff of two-node method are less than $20 \mathrm{pcm}$. Keff calculated by two-node method using $1.26 \mathrm{~cm} \times 1.26 \mathrm{~cm}$ mesh size is more accurate than that by FMFD using $0.63 \mathrm{~cm} \times 0.63 \mathrm{~cm}$ mesh size, even using $0.315 \mathrm{~cm} \times 0.315 \mathrm{~cm}$ mesh size.

Since the difference of Keff between axial mesh size of $1.27 \mathrm{~cm}$ and $2.54 \mathrm{~cm}$ can be ignored, axial mesh size of $2.54 \mathrm{~cm}$ is sufficiently accurate in practical calculation. Therefore, from the perspective of engineering applications, two-node method using $1.26 \mathrm{~cm} \times 1.26 \mathrm{~cm} \times 2.54 \mathrm{~cm}$ mesh size meets the accuracy requirements of practical engineering simulations.

The computing time is given in Table 4. All calculations are executed using 400 cores. The computing time of two-node with $1.26 \mathrm{~cm} \times 1.26 \mathrm{~cm} \times 2.54 \mathrm{~cm}$ mesh size is $11 \%$ of FMFD with $0.315 \mathrm{~cm} \times 0.315 \mathrm{~cm} \times 2.54 \mathrm{~cm}$ mesh size, $\sim 70 \%$ of FMFD with $0.63 \mathrm{~cm} \times 0.63 \mathrm{~cm} \times 2.54 \mathrm{~cm}$. It takes $\sim 9$ core 
hours to perform a pin-by-pin 7 groups calculation of a practical three-dimensional $1 / 4$ reactor with an acceptable accuracy.

\begin{tabular}{|c|c|c|c|c|c|c|c|}
\hline $\begin{array}{l}\mathrm{U} 0 \mathrm{X}-2 \\
(\mathrm{BA1C})\end{array}$ & MOX-1 & $\begin{array}{l}\text { U0X-2 } \\
\text { (BA16) } \\
\end{array}$ & UOX -2 & $\begin{array}{c}\text { MOX-1 } \\
\text { (BA8) } \\
\end{array}$ & $\mathrm{U} 0 \mathrm{X}-1$ & $\begin{array}{c}\text { M0X-1 } \\
(\text { BA8) }\end{array}$ & UOX -1 \\
\hline MOX -1 & $\begin{array}{l}\text { UOX-2 } \\
\text { (BA1C) }\end{array}$ & UOX-2 & MOX -1 & UOX-1 & $\begin{array}{c}\text { MOX-1 } \\
\text { (BA8) }\end{array}$ & UOX -2 & MOX-1 \\
\hline $\begin{array}{l}\mathrm{UOX}-2 \\
(\mathrm{BA} 1 \mathrm{C})\end{array}$ & UOX-2 & $\begin{array}{c}\text { MOX-1 } \\
\text { (BA8) }\end{array}$ & UOX-2 & MOX-1 & UOX -2 & MOX -1 & $\mathrm{UOX}-1$ \\
\hline UOX -2 & MOX-1 & UOX-2 & $\begin{array}{c}\text { MOX-1 } \\
(\mathrm{BA} 8)\end{array}$ & UOX-2 & $\begin{array}{l}\text { UOX-2 } \\
\text { (BA1C) }\end{array}$ & UOX -1 & \\
\hline $\begin{array}{c}\text { MOX-1 } \\
(\mathrm{BA} 8) \\
\end{array}$ & UOX -1 & MOX-1 & UOX -2 & $\begin{array}{l}\text { UOX-2 } \\
(\mathrm{BA} 16)\end{array}$ & $\mathrm{U} 0 \mathrm{X}-1$ & MOX -1 & \\
\hline UOX -1 & $\begin{array}{r}\text { MOX-1 } \\
\text { (BA8) }\end{array}$ & UOX-2 & $\begin{array}{l}\text { UOX-2 } \\
\text { (BA1C) }\end{array}$ & UOX -1 & MOX-1 & & \\
\hline $\begin{array}{c}\text { MOX-1 } \\
(\mathrm{BA} 8) \\
\end{array}$ & UOX-2 & MOX-1 & UOX -1 & MOX-1 & & & \\
\hline UOX -1 & MOX-1 & UOX-1 & & & & & \\
\hline
\end{tabular}

(a) Lower half of the active zone

\begin{tabular}{|c|c|c|c|c|c|c|c|}
\hline $\begin{array}{l}\mathrm{UOX}-2 \\
(\mathrm{BA} 1 \mathrm{f})\end{array}$ & MOX-1 & $\begin{array}{l}\text { UOX-2 } \\
(\text { BA16) }\end{array}$ & $\begin{array}{c}\text { UOX-2 } \\
\text { (CR) }\end{array}$ & $\begin{array}{c}\text { MOX-1 } \\
\text { (BA8) }\end{array}$ & UOX-1 & $\begin{array}{c}\text { M0X-1 } \\
\text { (BA8) }\end{array}$ & UOX-1 \\
\hline MOX-1 & $\begin{array}{l}\text { UOX-2 } \\
\text { (BA16) }\end{array}$ & $\begin{array}{c}\text { UOX-2 } \\
\text { (CR) }\end{array}$ & MOX-1 & UOX-1 & $\begin{array}{c}\text { MOX-1 } \\
\text { (BA8) }\end{array}$ & $\begin{array}{c}\text { UOX-2 } \\
\text { (CR) }\end{array}$ & MOX-1 \\
\hline $\begin{array}{l}\text { UOX-2 } \\
(B A 16)\end{array}$ & $\begin{array}{c}\mathrm{UOX}-2 \\
\text { (CR) }\end{array}$ & $\begin{array}{c}\text { MOX-1 } \\
\text { (BA8) }\end{array}$ & $\begin{array}{c}\text { UOX-2 } \\
\text { (CR) }\end{array}$ & MOX-1 & $\begin{array}{c}\text { UOX-2 } \\
\text { (CR) }\end{array}$ & MOX -1 & UOX -1 \\
\hline $\begin{array}{c}\mathrm{UOX}-2 \\
\text { (CR) }\end{array}$ & MOX-1 & $\begin{array}{c}\text { UOX-2 } \\
\text { (CR) }\end{array}$ & $\begin{array}{c}\text { M0X-1 } \\
\text { (BA8) }\end{array}$ & $\begin{array}{c}\text { UOX }-2 \\
\text { (CR) }\end{array}$ & $\begin{array}{l}\text { UOX-2 } \\
(\text { BA16) }\end{array}$ & UOX -1 & \\
\hline $\begin{array}{r}\text { MOX-1 } \\
(\mathrm{BA} 8)\end{array}$ & UOX-1 & MOX-1 & $\begin{array}{c}\text { UOX-2 } \\
\text { (CR) }\end{array}$ & $\begin{array}{l}\mathrm{UOX}-2 \\
(\mathrm{BA} 1 \mathrm{C})\end{array}$ & UOX -1 & MOX-1 & \\
\hline UOX-1 & $\begin{array}{c}\text { M0X-1 } \\
\text { (BA8) }\end{array}$ & $\begin{array}{c}\text { UOX-2 } \\
\text { (CR) }\end{array}$ & $\begin{array}{l}\text { UOX-2 } \\
(B A 16)\end{array}$ & UOX-1 & MOX-1 & & \\
\hline $\begin{array}{c}\text { MOX-1 } \\
\text { (BA8) }\end{array}$ & $\begin{array}{c}\text { UOX-2 } \\
\text { (CR) }\end{array}$ & MOX-1 & $\mathrm{UOX}-1$ & MOX-1 & & & \\
\hline UOX-1 & MOX-1 & UOX-1 & & & & & \\
\hline
\end{tabular}

(b) Upper half of the active zone

Figure 4. Layout of Self-constructed Problem

Table III. Keff Comparison of Self-constructed Problem

\begin{tabular}{|c|c|c|}
\hline Mesh, cm & $\begin{array}{c}\text { Keff (Error of } \\
\text { reactivity, pcm) of } \\
\text { two-node }\end{array}$ & $\begin{array}{c}\text { Keff (Error of reactivity, } \\
\text { pcm) of FMFD }\end{array}$ \\
\hline $1.26 \times 1.26 \times 2.54$ & $1.13534(13)$ & $1.13867(271)$ \\
\hline $0.63 \times 0.63 \times 2.54$ & $1.13540(18)$ & $1.13655(107)$ \\
\hline $0.315 \times 0.315 \times 2.54$ & $1.13516(-1)$ & $1.13555(29)$ \\
\hline $0.315 \times 0.315 \times 1.27$ & $1.13517(-)$ & $1.13556(30)$ \\
\hline
\end{tabular}


Table IV. Computing Time of Self-constructed Problem

\begin{tabular}{|c|c|c|}
\hline Mesh, $\mathrm{cm}$ & Wall time of two-node, $\mathrm{s}$ & Wall time of FMFD, $\mathrm{s}$ \\
\hline $1.26 \times 1.26 \times 2.54$ & 77 & 24 \\
\hline $0.63 \times 0.63 \times 2.54$ & 309 & 110 \\
\hline $0.315 \times 0.315 \times 2.54$ & 1653 & 689 \\
\hline $0.315 \times 0.315 \times 1.27$ & 5379 & 2109 \\
\hline
\end{tabular}

\section{CONCLUSIONS}

In this paper, a simplified two-node method is proposed to discretize the SP3 equations, and the CORCAPIN code is developed. The numerical results show that: 1) The calculation accuracy of two-node method using $n \times n$ meshes per cell is better than that of FMFD using $2 n \times 2 n$ meshes per cell significantly. 2) The efficiency of two-node method using $1 \times 1$ mesh per cell increases by one order of magnitude compared to that of FMFD using $4 \times 4$ meshes per cell. 3) Relative errors of pin power of two-node method using $1 \times 1$ mesh per cell are within $5 \%$, errors of Keff are within $200 \mathrm{pcm}$. 4) It takes $\sim 9$ core hours to perform a pinby-pin 7 groups calculation of a practical three-dimensional $1 / 4$ reactor using $1 \times 1$ mesh per cell.

\section{REFERENCES}

1. M. Tatsumi, A. Yamamoto., "Advanced PWR core calculation based on multi-group nodal-transport method in three-dimensional pin-by-pin geometry," Journal of Nuclear Science and Technology, 40(6), pp. 376-387 (2003).

2. W. Yang, H. Wu, Y. Li, et al., "Acceleration of the exponential function expansion nodal SP3 method by multi-group GMRES algorithm for PWR pin-by-pin calculation," Annals of Nuclear Energy, 120, pp. $869-879$ (2018).

3. A. Calloo, D. Couyras, F. Fevotte, et al, "COCAGNE: EDF New Neutronic Core Code for ANDROMEDE Calculation Chain," M\&C 2017, Jeju, Korea (2017).

4. Z. Ning, Three-dimensional fine mesh flux expansion nodal method based on non-linear iterative strategy, Nuclear Power Institute of China, Chengdu, China (2016).

5. J. Kim, Y. Kim, "Development of 3-D HCMFD algorithm for efficient pin-by-pin reactor analysis," Annals of Nuclear Energy, 127, pp.87-98 (2019).

6. T. Lin, Y. Liu, "A Next Generation Method for Light Water Reactor core analysis by using Global/Local Iteration Method with SP3," Annals of Nuclear Energy, 118, pp. 49-60 (2018).

7. Y. Chao, "A new SPn theory formulation with self-consistent physical assumptions on angular flux," Annals of Nuclear Energy, 87, pp. 137-144 (2016).

8. J. E. Roman, C. Campos, E. Romero, A. Tomas, SLEPc Users Manual, Tech. Rep. DSIC-II/24/02 Revision 3.8, Universitat of Politecnica de Valencia (2017).

9. S. Balay, S. Abhyankar, M. Adams and et al, PETSc Users manual, Tech. Rep. ANL-95/11 - Revision 3.8, Argonne National Laboratory (2017).

10. W. Yang, Study on PWR Three-dimensional Whole-core Pin-by-pin Physical Calculation Method, Xi' an Jiaotong University, Xi'an, China (2018).

11. N. Z. CHO, "KAIST Nuclear Reactor Analysis and Particle Transport Laboratory, Benchmark Problem 1A," http://nurapt.kaist.ac.kr/benchmark. 